\title{
The impact of academic stress on medical students attending college in the Inner Mongolia Area of China*
}

\author{
Jie Chen ${ }^{1}$, Yanyan $\mathrm{Wu}^{1}, \mathrm{He} \mathrm{Yi}^{1},{\text { Zhijun } \mathrm{Li}^{1} \text {, Yuki Eshita }}^{2}$, Peng Qin ${ }^{3}$, Lifu Chen ${ }^{4}$, Juan Sun ${ }^{1 \#}$ \\ ${ }^{1}$ Department of Public Health, Inner Mongolia Medical College, Hohhot, China; ${ }^{\#}$ Corresponding Author: cnsunjuan@yahoo.com.cn \\ ${ }^{2}$ Faculty of Medicine, Oita University, Oita, Japan \\ ${ }^{3}$ Department of Computing Center, People’s Hospital of Inner Mongolia Autonomous Region, Hohhot, China \\ ${ }^{4}$ Tongliao Hospital, Tongliao, China
}

Received 10 January 2013; revised 28 February 2013; accepted 10 April 2013

Copyright (c) 2013 Jie Chen et al. This is an open access article distributed under the Creative Commons Attribution License, which permits unrestricted use, distribution, and reproduction in any medium, provided the original work is properly cited.

\begin{abstract}
The aim of this study was to examine whether student characteristics affect the risk of health conditions, and explore whether the degree of academic stress affects the level of distress. We surveyed medical students in the Inner Mongolia Medical College China using a questionnaire. A logistic regression analysis was used to ascertain factors associated with distress. The Wilcoxon Mann-Whitney test was used to determine the relationship between distress and different academic stress levels. Of the 6044 students completing questionnaires, $47.5 \%$ self-reported distressing body symptoms induced by academic stress. Chi square tests showed statistically significant associations between distress and gender, academic stress, and residence; feeling academic stress caused a more than $\mathbf{1 . 5}$ times risk of distress. Gender and academic stress were significantly associated with distress in non-conditional binary logistic regression models. Compared with male students, female students was more likely to feel distress. The Wilcoxon Mann-Whitney test also showed that the distress rate increased with academic stress and a dose-response relationship between the distress rate and stress level was found. The present study indicates that it is important to reduce academic stress and manage it in order that better outcomes be achieved in regard to distress, especially in females.
\end{abstract}

\section{Keywords: Academic Stress; Distress; College}

*Competing interests: The author declares that he has no competing interests.
Students

\section{INTRODUCTION}

Global health programs are becoming much more common at academic health centers, varying from comprehensive, multidisciplinary, multi-professional initiatives that include patient care, research, and education components, to individual courses [1]. For example, research in mental health has demonstrated that university students experience high levels of psychological distress and depression, with as many as $10 \%-50 \%$ of subjects clinically afflicted [2]. Stress is also a trigger for many complaints and medical conditions and some investigators suggest the use of a "bio-psychosocial" model in this context, which emphasizes the role of the psychological factors [3].

The period of undergraduate education is a sensitive time in the life of an individual [4], and for many young adults college has been found to be stressful [3]. Past research has determined that the stressors involved include: academics, social relationships, finances, daily hassles, and familial relationships [5]. Examinations and assessments constitute one source of academic stress [6], and in recent years, considerable research has been conducted on nursing students [7] and medical students to better understand the nature of this stress [8]. In general, North American and European studies dominate the field with a focus on medical students [8]; these studies have examined depression, stress, anxiety, and burnout reactions [9]. Some studies show gender differences [10-12] while others do not [13,14].

Research on stress and the resulting distress experienced by individuals began in the 1930s [15]. Today, we live in a smaller world with a larger sense of instant 
connectedness on a global scale [1] and thus there is increasing interest to look at the results of studies in different countries and populations and see what can be learned and applied. However, most studies focus on one category of illness. For example, the prevalence and characteristics of headache in Brazil [16], Europe [17], Nigeria [18], and Turkey [19], the trigger factors for headache [20], and the relationship between stress and gastrointestinal upset and headaches [21,22], and anorexia [23].

As mentioned earlier, most studies have been geographically focused on countries in North America and Europe. However, the pressure to perform in school is considerably more acute in Asian societies [24]. Consequently, in the context of initiatives involving collaborative efforts among schools of medicine, public health, nursing, and dentistry [1] with regard to bio-psycho-social medical models, we were interested in examining how academic stress affects the risk of body distress in medical students in the Inner Mongolia Autonomous Region of China. Given the limited data available we hoped that the results could be used to provide advice to students and help us develop appropriate assistance programs.

\section{MATERIALS AND METHODS}

The data analysed in our study came from a questionnaire recently conducted in the Inner Mongolia Medical College of China [25,26] from December 2010 to January 2011 in which undergraduate students living on campus were surveyed [26]. The survey consisted of inquiries about basic demographic data (including sex, age, nationality, and faculty), living habits, feelings, and thoughts experienced during college.

There are 56 nationalities in China: the Han nationality being the majority, along with 55 other minorities. Although Mongolian is the main minority in the Inner Mongolia Autonomous Region, we also included other minorities. Academic stress was defined as "I find myself very concerned about the grades I am likely to receive this semester", "I am spending a lot of time thinking about how this semester's grades could negatively affect my educational and career goals", "I am worrying a great deal about the effect this semester's grades will have on my future", and "I find myself very concerned about the grades I am likely to receive this semester". These items have previously been used in research on academic stress and health and were created to focus on grades because grades have emerged as a key stressor in studies of academic stress [27]. We also defined students who came from a city or suburb as urban, and those from a village or pastoral area as rural. We defined having distress as having at least one symptom of headache, gastrointesti- nal upset, no appetite, or other distressful symptom.

We entered quantitative data using EpiDate 3.1 with cross-checking carried out by operators to prevent any input error. We analyzed the data using SPSS version 13.0. A chi square test was performed on the selected factors. A non-conditional binary logistic regression analysis was used to ascertain factors associated with distress. The influence of academic stress level on distress for male and female students was determined using the Wilcoxon Mann-Whitney test. Using the data of academic stress level and distress rate, we developed a table by gender. The distress prevalence of year of study was calculated in female medical students. Pearson correlative analysis was performed between year of study and distress for female students. Then we assessed the prevalence of distress for various faculties among Inner Mongolia Medical College by gender. All statistical tests were 2-tailed with $\mathrm{p}<0.05$ considered statistically significant.

Ethical Approval to conduct the study in which consent was needed from all study participants was obtained from the Ethical Committee of Inner Mongolia [26]. We obtained approval from the college management office and from faculties in which the study would be carried out. In cooperation with the different faculty management bodies, we informed students about the purposes of the study before filling out the questionnaire. We advised students that participation was voluntary, and that there was a privacy protection policy for personal and enrollment data. All participants who completed the questionnaire in classrooms provided informed consent.

\section{RESULTS}

Of the 6047 students who completed the original questionnaire $29.4 \%$ were male and $70.6 \%$ female [26]. The average age was $21 \pm 1.5$ years. The test-retest reliability was 96. 4\%, the range of the Kappa index 6.03 - 8.03, and the mean value of the Kappa index 7.13 [26].

Of the students, $47.5 \%$ self-reported distress. The result of chi square tests showed statistically significant associations between distress and gender, academic stress, and residence (Table 1). Distress rate was significantly different by gender in univariate analyses, with females having a higher rate of stress than males. Students with academic stress were more also likely to have distress. Urban students had a significantly lower distress rate than those residing in a rural area. However, while the rate of distress for the majority students was lower than Mongolian and other minorities, this difference was not statistically significant.

Gender and academic stress were significantly associated with distress in the non-conditional binary logistic regression models (Table 2). Compared with male students, female students were more likely to feel distress. 
Table 1. Description and comparison of selected characteristics and prevalence of distress in Inner Mongolia Medical College students.

\begin{tabular}{|c|c|c|c|c|c|}
\hline \multirow{2}{*}{ Characteristic } & \multirow{2}{*}{$\mathbf{n}$} & \multicolumn{2}{|c|}{ Distress } & \multirow{2}{*}{$\mathrm{Chi}^{2}$} & \multirow{2}{*}{$\mathbf{P}$} \\
\hline & & $\mathbf{n}$ & $\%$ & & \\
\hline \multicolumn{6}{|l|}{ Gender } \\
\hline Male & 1775 & 770 & 43.4 & 16.94 & $<0.0005$ \\
\hline Female & 4269 & 2101 & 49.2 & & \\
\hline \multicolumn{6}{|l|}{ Ethnic } \\
\hline Majority & 4318 & 2031 & 47.0 & & \\
\hline Mongolia & 1405 & 673 & 47.9 & 3.10 & 0.212 \\
\hline Other minority & 167 & 840 & 52.0 & & \\
\hline \multicolumn{6}{|l|}{ Residence } \\
\hline Urban & 2485 & 1109 & 44.6 & 13.92 & $<0.0005$ \\
\hline Rural & 3537 & 1751 & 49.5 & & \\
\hline \multicolumn{6}{|l|}{ Academic stress } \\
\hline Yes & 5568 & 2691 & 48.3 & 19.44 & $<0.0005$ \\
\hline No & 476 & 180 & 37.8 & & \\
\hline
\end{tabular}

Table 2. Logistic regression for factors of distress for Inner Mongolia Medical College students.

\begin{tabular}{|c|c|c|c|c|c|}
\hline Characteristic & B & $\mathrm{SE}$ & $\mathbf{P}$ & OR & $95 \%$ CI \\
\hline \multicolumn{6}{|l|}{ Gender } \\
\hline Male & - & - & - & 1.00 & \\
\hline Female & 0.209 & 0.058 & $<0.0005$ & 1.23 & $1.10-1.38$ \\
\hline Age & -0.020 & 0.018 & 0.277 & 0.98 & $0.95-1.02$ \\
\hline \multicolumn{6}{|l|}{ Ethnic } \\
\hline Majority & - & - & - & 1.00 & - \\
\hline Mongolia & -0.025 & 0.062 & 0.688 & 0.98 & $0.86-1.10$ \\
\hline Other minority & -0.081 & 0.117 & 0.489 & 0.92 & $0.73-1.16$ \\
\hline \multicolumn{6}{|l|}{ Residence } \\
\hline Urban & - & - & - & 1.00 & - \\
\hline Rural & 0.006 & 0.053 & 0.910 & 1.01 & $0.91-1.12$ \\
\hline \multicolumn{6}{|l|}{ Academic stress } \\
\hline No & - & - & - & 1.00 & - \\
\hline Yes & 0.416 & 0.100 & $<0.0005$ & 1.516 & $1.25-1.85$ \\
\hline
\end{tabular}

SE: standard error; OR: odd ratio; CI: confidence interval.

In addition, those students who self-reported feeling academic stress had more than a 1.5 times higher risk of having distress. Although there was an association between residence and distress in the univariate analyses, no association was found in the multivariate analysis.

In analysing the associations between academic stress level and distress rate by gender because we found gender differences regarding distress in the multivariate analysis, the result of Wilcoxon Mann-Whitney test showed that the distribution of the distress rate was significantly different in respect of academic stress level for both genders, with the distress level increasing with the academic stress. This suggests a dose-response relationship between these parameters. Compared with males, females have higher rate of distress at all academic stress levels.

Prevalence of distress in female medical students by year of study was showed in Table 3. Distress of the female medical students was observed to be positively correlated to year of study from Pearson correlative analysis $(r=0.926, p=0.024)$.

The prevalence range of distress for various faculties' student with academic stress was from $45.7 \%$ to $51.1 \%$ in Table 4. There was no significant difference in preva-

Table 3. Prevalence of distress in female medical students.

\begin{tabular}{ccc}
\hline Year of study & $\mathbf{n}$ & $\mathbf{n} / \mathbf{N}(\%)$ \\
\hline 1 & 872 & 46.8 \\
2 & 619 & 46.9 \\
3 & 457 & 54.5 \\
4 & 109 & 57.4 \\
5 & 44 & 73.3 \\
\hline
\end{tabular}


Table 4. Prevalence of distress for various faculties students with academic stress by gender.

\begin{tabular}{|c|c|c|c|c|c|}
\hline \multirow{2}{*}{ Faculty } & \multirow{2}{*}{ Total prevalence } & \multicolumn{2}{|c|}{ Male } & \multicolumn{2}{|c|}{ Female } \\
\hline & & $\mathbf{n}$ & $\%$ & $\mathbf{n}$ & $\%$ \\
\hline Clinical Medicine & 45.7 & 283 & 41.5 & 637 & 47.8 \\
\hline Traditional Chinese Mongolian Medicine & 49.8 & 161 & 49.2 & 312 & 50.1 \\
\hline Medicine & 48.9 & 124 & 47.9 & 297 & 49.3 \\
\hline Nurse & 51.1 & 14 & 51.9 & 165 & 51.1 \\
\hline Public Health Administration/Medicine Information Management & 47.7 & 97 & 42.0 & 251 & 50.3 \\
\hline Other & 48.0 & 32 & 40.5 & 276 & 49.0 \\
\hline
\end{tabular}

lence of distress among various faculties $(p=0.174)$. Females' prevalence higher than male's for various faculties except for the faculty of Nurse.

\section{DISCUSSION}

Kanter noted a rapidly growing interest in matters of world health by students and residents, as well as by leaders of medical schools and teaching hospitals [1], which prompted us to conduct our study of medical students. Resident's personal characteristics were closely related to stress and burnout [28]. The findings of the present study show that college students in general have academic stress and that there is a significant positive relationship of academic stress with resultant distress. Past research has found much evidence to support the stress-illness relationship [29], and findings from the current study expand our awareness of the stress-illness paradigm.

The results of the current study also provide some support for sex differences regarding induced distress in college students with females suffering higher levels of distress. Numerous studies have highlighted that women report more illness and stress than men in general. For example, Marianne et al noted that based on individual discomfort and effort scores, discomfort was somewhat higher among the females, whereas effort was somewhat higher for males, although sex differences were not significant [30]. While Dyson and Renk found no sex differences in college students' reported stress levels for college [31], Our result was similar to that of BarraAlmagia who reported that compared to males, adolescent females reported higher levels of health problems [32]. Authors of another study indicated that health complaints were significantly more frequent in female physicians but decreased with age. Low job satisfaction, high job stress, and emotional distress were all found to be significant predictors of subjective health complaints, as measured by the Ursin Health Inventory [33]. Other research has demonstrated that although men easily get symptoms, while women tend to engage in healthpromoting behaviors and men engage in health-risky behaviours [34]. One of the reasons for a higher distress level in females is that compared to males, females face more stress [4] and there are innate differences in physical factors by gender. Further study showed that the highest year of study had the highest distress prevalence in female with academic stress. The senior class students ought to receive the most attention in terms of preventive education.

The findings of our study indicate that the distress level increases with higher levels of academic stress regardless of gender. While research has demonstrated that stress generates a robust rise of stress hormones, autonomic measures, and immune parameters, other physiological and psychological responses do not or only poorly correlate [35]. Moreover, for potential underlying mechanisms, including the immediacy of physiological reactions to stressors, individuals have a wide variety of responses concerning stressor-physical symptom relationships [36]. Nevertheless, under stress, sympathetic nerve activity increases and parasympathetic nerve activity decreases [37], headaches with autonomic symptoms are accompanied by autonomic reactions, which are dependent on activity in cranial parasympathetic neurons [38], and gastrointestinal problems are significantly related to more stressors than other symptoms examined [36]. No significant difference was found between distress prevalence and various faculties' students with academic stress. Further research is necessary to confirm these results in other universities.

We did not find that the level of distress varied among different ethnic groups even though Inner Mongolia is considered one of China's five minority areas. We speculate that the reason for this result could be because these ethnic groups have resided in the area a long time [26].

There are limitations to this study. Distress was assessed on the basis of self-reported data only, without the use of biochemical measurements.

Our investigation demonstrates that academic stress 
triggers body distress symptoms in medical students. While we know that college students often face serious academic stress, the result is that higher academic stress levels generate highCer levels of body distress. Of most interest is that females are more likely to have distress symptoms when they feel academic stress. All of these results suggest that it is useful to make students very aware of the problems associated with academic stress when they arrive at medical school, especially female students. Kanter's point that the if the pressure on the medical school curriculum is relieved by creating requirements that shift coursework to the undergraduate curriculum, the quality of premedical education will be eroded [39] is well taken. In other words, we must deal with the level of academic stress generated at medical school by helping the students themselves to deal directly with the stress, and not making life easier at medical school.

\section{REFERENCES}

[1] Kanter, S.L. (2008) Global health is more important in a smaller world. Academic Medicine, 83, 115-116. doi:10.1097/01.ACM.0000305155.66318.58

[2] Christensson, A., Runeson, B., Dickman, P.W. and Vaez, M. (2010) Change in depressive symptoms over higher education and professional establishment-A longitudinal investigation in a national cohort of Swedish nursing students. BMC Public Health, 10, 343. doi:10.1186/1471-2458-10-343

[3] Penacoba-Puente, C., Fernandez-de-Las-Penas, C., Gonzalez-Gutierrez, J.L., Miangolarra-Page, J.C. and Pareja, J.A. (2008) Interaction between anxiety, depression, quality of life and clinical parameters in chronic tension-type headache. European Journal of Pain, 12, 886-894. doi:10.1016/j.ejpain.2007.12.016

[4] Pierceall, E.A. and Keim, M.C. (2007) Stress and coping strategies among community college students. Community College Journal of Research and Practice, 31, 703712. doi:10.1080/10668920600866579

[5] Brougham, R., Zail, C., Mendoza, C. and Miller, J. (2009) Stress, sex differences, and coping strategies among college students. Current Psychology, 28, 85-97. doi:10.1007/s12144-009-9047-0

[6] Gibbons, C., Dempster, M. and Moutray, M. (2011) Stress, coping and satisfaction in nursing students. Journal of Advanced Nursing, 67, 621-632. doi:10.1111/j.1365-2648.2010.05495.x

[7] Freeburn, M. and Sinclair, M. (2009) Mental health nursing students' experience of stress: Burdened by a heavy load. Journal of Psychiatric and Mental Health Nursing, 16, 335-342. doi:10.1111/j.1365-2850.2008.01376.x

[8] Dyrbye, L.N., Thomas, M.R. and Shanafelt, T.D. (2006) Systematic review of depression, anxiety, and other indicators of psychological distress among US and Canadian medical students. Academic Medicine, 81, 354-373. doi:10.1097/00001888-200604000-00009
[9] Dyrbye, L.N., Thomas, M.R., Huschka, M.M., Lawson, K.L., Novotny, P.J., Sloan, J.A. and Shanafelt, T.D. (2006) A multicenter study of burnout, depression, and quality of life in minority and nonminority US medical students. Mayo Clinic Proceedings, 81, 1435-1442. doi:10.4065/81.11.1435

[10] Rosal, M.C., Ockene, I.S., Ockene, J.K., Barrett, S.V., Ma, Y. and Hebert, J.R. (1997) A longitudinal study of students' depression at one medical school. Academic Medicine, 72, 542-546. doi:10.1097/00001888-199706000-00022

[11] Helmers, K.F., Danoff, D., Steinert, Y., Leyton, M. and Young, S.N. (1997) Stress and depressed mood in medical students, law students, and graduate students at McGill University. Academic Medicine, 72, 708-714. doi:10.1097/00001888-199708000-00018

[12] Dahlin, M., Joneborg, N. and Runeson, B. (2005) Stress and depression among medical students: A cross-sectional study. Medical Education, 39, 594-604. doi:10.1111/j.1365-2929.2005.02176.x

[13] Guthrie, E., Black, D., Bagalkote, H., Shaw, C., Campbell, M. and Creed, F. (1998) Psychological stress and burnout in medical students: A five-year prospective longitudinal study. Journal of the Royal Society of Medicine, 91, 237243.

[14] Tyssen, R., Vaglum, P., Gronvold, N.T. and Ekeberg, O. (2001) Suicidal ideation among medical students and young physicians: A nationwide and prospective study of prevalence and predictors. Journal of Affective Disorders, 64, 69-79. doi:10.1016/S0165-0327(00)00205-6

[15] Selye, H. (1985) The nature of stress. The Best of Basal Facts, 7, 3-11.

[16] Falavigna, A., Teles, A.R., Velho, M.C., Vedana, V.M., Silva, R.C., Mazzocchin, T., Basso, M. and Braga, G.L. (2010) Prevalence and impact of headache in undergraduate students in Southern Brazil. Arquivos de NeuroPsiquiatria, 68, 873-877. doi:10.1590/S0004-282X2010000600008

[17] Jensen, R., Mitsikostas, D.D., Valade, D. and Antonaci, F. (2010) Guidelines for the organization of headache education in Europe: The headache school II. The Journal of Headache and Pain, 11, 161-165. doi:10.1007/s10194-010-0195-2

[18] Ojini, F.I., Okubadejo, N.U. and Danesi, M.A. (2009) Prevalence and clinical characteristics of headache in medical students of the University of Lagos, Nigeria. Cephalalgia, 29, 472-477. doi:10.1111/j.1468-2982.2008.01766.x

[19] Bicakci, S., Over, F., Aslan, K., Bozdemir, N., Saatci, E. and Sarica, Y. (2007) Headache characteristics in senior medical students in Turkey. The Tohoku Journal of Experimental Medicine, 213, 277-282. doi:10.1620/tjem.213.277

[20] Nash, J.M. and Thebarge, R.W. (2006) Understanding psychological stress, its biological processes, and impact on primary headache. Headache: The Journal of Head and Face Pain, 46, 1377-1386. doi:10.1111/j.1526-4610.2006.00580.x

[21] Kubo, M., Fujiwara, Y., Shiba, M., Kohata, Y., Yamagami, 
H., Tanigawa, T., Watanabe, K., Watanabe, T., Tominaga, K. and Arakawa, T. (2011) Differences between risk factors among irritable bowel syndrome subtypes in Japanese adults. Neurogastroenterology \& Motility, 23, 249254. doi:10.1111/j.1365-2982.2010.01640.x

[22] Kaynak Key, F.N., Donmez, S. and Tuzun, U. (2004) Epidemiological and clinical characteristics with psychosocial aspects of tension-type headache in Turkish college students. Cephalalgia, 24, 669-674. doi:10.1111/j.1468-2982.2004.00736.x

[23] Attia, E. and Walsh, B.T. (2007) Anorexia nervosa. The American Journal of Psychiatry, 164, 1805-1810.

[24] Isralowitz, R.E. and Hong, O.T. (1990) Singapore youth: The impact of social status on perceptions of adolescent problems. Adolescence, 25, 357-362.

[25] Bian, J. (2012) Prevalence of and factors associated with various level of body weight among Inner Mongolia medical students in China. Open Journal of Preventive Medicine, 2, 123-130. doi:10.4236/ojpm.2012.22018

[26] Bian, J., Du, M.L., Liu, Z.Y., Fan, Y.C., Eshita, Y. and Sun, J. (2012) Prevalence of and factors associated with daily smoking among Inner Mongolia medical students in China: A cross-sectional questionnaire survey. Substance Abuse Treatment, Prevention, and Policy, 7, 20. doi:10.1186/1747-597X-7-20

[27] Hystad, S.W., Eid, J., Laberg, J.C., Johnsen, B. H. and Bartone, P.T. (2009) Academic stress and health: Exploring the moderating role of personality hardiness. Scandinavian Journal of Educational Research, 53, 421-429. doi:10.1080/00313830903180349

[28] Lue, B.H., Chen, H.J., Wang, C.W., Cheng, Y. and Chen, M.C. (2010) Stress, personal characteristics and burnout among first postgraduate year residents: A nationwide study in Taiwan. Medical Teacher, 32, 400-407. doi:10.3109/01421590903437188

[29] Segerstrom, S.C. and O’Connor, D.B. (2012) Stress, health and illness: Four challenges for the future. Psychology \& Health, 27, 128-140. doi:10.1080/08870446.2012.659516

[30] Frankenhaeuser, M., Von Wright, M.R., Collins, A., Von Wright, J., Sedvall, G. and Swahn, C.G. (1978) Sex dif- ferences in psychoneuroendocrine reactions to examination stress. Psychosomatic Medicine, 40, 334-343.

[31] Dyson, R. and Renk, K. (2006) Freshmen adaptation to university life: Depressive symptoms, stress, and coping. Journal of Clinical Psychology, 62, 1231-1244. doi:10.1002/jclp.20295

[32] Barra-Almagia, E. (2009) Influence of stress and depressed mood on adolescent health: Concurrent and prospective analysis. Universitas Psychologica, 8, 175-182.

[33] Aasland, O.G., Olff, M., Falkum, E., Schweder, T. and Ursin, H. (1997) Health complaints and job stress in Norwegian physicians: The use of an overlapping questionnaire design. Social Science \& Medicine, 45, 16151629. doi:10.1016/S0277-9536(97)00093-2

[34] Soffer, M. (2010) The role of stress in the relationships between gender and health-promoting behaviours. Scandinavian Journal of Caring Sciences, 24, 572-580. doi:10.1111/j.1471-6712.2009.00751.x

[35] Hellhammer, D.H., Stone, A.A., Hellhammer, J. and Broderick, J. (2010) Measuring Stress. Encyclopedia of Behavioral Neuroscience, 2, 186-191. doi:10.1016/B978-0-08-045396-5.00188-3

[36] Nixona, A.E., Mazzola, J.J., Bauera, J., Kruegerc, J.R. and Spectora, P.E. (2011) Can work make you sick? A meta-analysis of the relationships between job stressors and physical symptoms. Work \& Stress, 25, 1-22. doi:10.1080/02678373.2011.569175

[37] Saito, K., Hiya, A., Uemura, Y. and Furuta, M. (2008) Clinical training stress and autonomic nervous function in female medical technology students: Analysis of heart rate variability and 1/f fluctuation. The Journal of Medical Investigation, 55, 227-230. doi:10.2152/jmi.55.227

[38] Janig, W. (2003) Relationship between pain and autonomic phenomena in headache and other pain conditions. Cephalalgia, 23, 43-48. doi:10.1046/j.1468-2982.2003.00573.x

[39] Kanter, S.L. (2008) Toward a sound philosophy of premedical education. Academic Medicine, 83, 423-424. doi:10.1097/ACM.0b013e3181734623 